was done a short time ago, and I hear that the patient lived for about seven weeks after the exploration, losing flesh very rapidly. The morning before his desth be vomited frequently and passed blood by the rectum, together with some materia which resembled broken-down growth.

Biliary Colic caused by Appendicitis.

The vermiform appendix, when inflamed, may be an elusive organ, and there is scarcely any part of the abdomen in which it has not been found unexpectedly. The following is a case in which it was evidently the cause of biliary colic with jaundice, as the sequel proved.

I saw a young man with Dr. Lucss eighteen months ago, who for the two previous years hed been subject to attacks of colic on an average about once a month, which doubled him up, and were accompanied by jaundice, dark urine, and a tender spot just above the umbilicus. They resembled attacks of gall-stone colic, and became so severe that he willingly submitted to operation for their relief. At the operation a year ago I found the gall bladder whitish and tense, so tense that it could not be emptied until all the surrounding parts were made free. The gall bladder and cystic duct were firmly buried in strong adhesions which could only be separated with great difficulty No stone could be found anywhere, even in the ampulla, but two large glands were seen, one being deep down on the duodenum. The gall bladder was drained, and he remained well for seven weeks. The sequel explained the case.

He then had some pain in the lower abdomen, followed by a temperatare of $103^{\circ}$ F., and on account of his previous experience of pain rather delayed in requesting medi

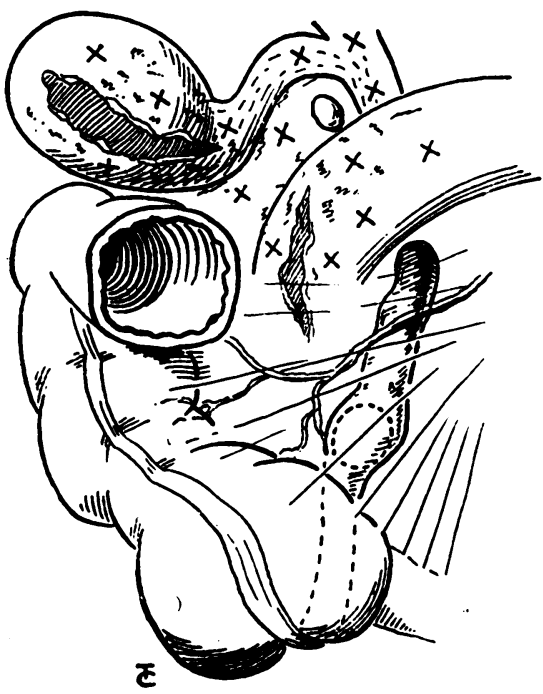
cal gid. Two days after the onset he was taken with collapse and violent pain, writhing with agony. I was sum moned and found him with slight jaundice, a running pulse of 156 , and signs of general peritonitis for which I operated at midnight, providing multiple drain age. Abundant curdy and bilestained fluid escaped from the incision and I removed gangrenous appen dix, with a concre tion which had all through. Now the tip of the appendix was close to the spine, above the umbilicus, and pointing upwards in thedirection of the sternum

(Fig. 5).

Filiary colic with jaundice, caused by

It was therefore quite evident that the appendix had been the cause of his previous biliary attacks and of the intimate adhesions found about the biliary apparatus at the time of the first operation, the explanation of which had been a mystery before. He is now, a year after the latter operation, perfectly well, and is rather proud of the fact that his biliary apparatus has been investigated, his appendix removed, and that he has been saved after general peritonitis with the aid of half a dozen drainage tubes.

I have referred to a few examples of the rarer associa tions of biliary trouble as a sort of sidelight on an important subject. We regard the possession of gall stones as a disesse, for which suffering humanity has to pay its price. Chinese doctors regard gall stones from another aspect, use them as medicine, and purchase them from Australian cattle dealers at a somewhat fancy cost, varying from 1s. to 10s. each, according to their size.

1 Greig Bmith, Abdominal RuFERENCES

, Abdominal Surgery, 1906, II, 970. 2 Brewer, Ann. Surg.

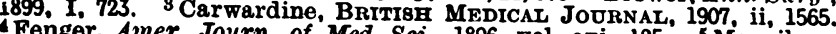
Abdominal Operations, of Med. Sci.. 1896, vol. cxi, 125. 'S Moynihan, 1908. xlviii. 676. 7 Mayo Robson, Disenses of the Gail Bladider and Bite Ducts, 1904, 215 .

THE New Year Honours were confined to the Indian Services. The only medical officer included is LieutenantColonel Joseph C. S. Vaughan, M.B., Superintendent, Campbell Medical School and Hospital, Calcutta, who is awarded the Kaisr-i.Hind Medal of the First Class.
THE FREQUENCY OF ADENO-CARCINOMA OF THE BODY IN FIBROID TUMOURS

\section{OF THE UTERUS,}

BASED ON A SERIES OF TWO HUNDRED CASES OF ABDOMINAL', HYSTERECTOMY.

By J. M. MUNRO KERR, M.D.,

GYNAECOLOGIST, WESTERN INFIRMARY, GLASGOW.

Is the present short communication it is my desire to indicate the frequency with which fibromyomata are invaded by malignant disease.

This matter has been receiving increasing attention in recent years, and as a result gynaecologists are forced to admit that malignant invasion and degeneration are more frequent than was supposed. This opinion has not been hurriedly reached; it has been formed slowly and after many years of observation. A few years ago a fibromyoma was looked upon as an absolntely benign growth, and operation was only recommended if symptoms were producing great discomfort; but year by year we have been forced to admit that malignant invasion and degeneration is by no means infrequent-in fact, that it occurs in from 3 per cent. to 5 per cent. of all fibromyomata removed.

On looking over the records of my cases I find that I have performed abdominal hysterectomy for fibroid tamours 200 times. In these cases I have found malig. nant disease on 9 occssions (sarcoma 2, adeno-carcinoma of the body of the uterus 6 , and carcinoma of the cervix 1 ).

of the 2 cases of sarcoma, one was undoubtedly a fibroid, which remained for many years quite inert in the abdomen, and then took on malignant degeneration. I can speak of this case with certainty, because I saw the patient with her medical attendant eight years before her death. Another gynaecologist at that time recommended leaving the crse alone, as the patient was then over 50 years of age and the tumour was causing her comparatively little trouble. I was opposed to expectancy, but the patient was very pleased to escape an operation, and expectancy was decided upon. After an interval of seven years I was asked to see this patient again, and I found her extremely emaciated, with an enormous hard, irregular tumour in the abdomen. As the case was too hopeless for operation she was admitted to a medical ward in the Western Infirmary, where she died a fow weeks later. A post-mortem examination was made, and the whole tumour and uterus removed and microscopically examined in the Pathological Institute. The tumour presented the typical appearance of a round-celled sarcoma.

In the other case the sarcoma was also of the round. celled variety, and although I feel convinced the tumour was originally a fibroid, I had no absolute proof of this, as the patient presented no symptoms and was only under medical observation a fow days before operation. The tumour was limited to the posterior wall of the uterus, and presented the typical appearance of a fibromyoma. Upon microscopic examination, however, it proved to be a round-celled sarcoma, and the patient died some eighteen months after operation of sarcoma of the lung.

Regarding the 6 cases in which an adeno.carcinoma had extended from the mucous membrane of the uterus, in four the fibroid tumours were of large dimensions and in two small and multiple. One of the cases had been under the care of another gynaecologist for four years. She was a lady 53 years of age, and it was hoped that with the menopsuse the tumour would shrink; but the menopause never came, and the tumour began to increase in size. I removed the uterus and she made a most satisfactory recovery from the operation, but she died some months later from a recurrence in the bowel.

In other cases it was impossible to say how long the fibroid tumours had been present before adeno-carcinoma developed.

My experience, then, in 200 fibroid tumours of the uterus removed by abdominal hysterectomy is that in nearly 5 per cent. malignant degeneration or invasion was present.

Turning now to some operators who have considered this subject, I find records of very similar experiences. 
Noble ${ }^{1}$ in 1,118 collected cases found carcinoma of the body in 29 (2.4 per cent.), epithelioma of the cervix uteri in 12 ( 1 per cent.), sarcoma in 22 (1.8 per cent.), chorionepithelioma in 2 ( 0.16 per cent.). Another American writer who has very recently discussed this subject, Ellice MacDonald, found in 700 cases of fibromyomata malignant disease present in 35 ( 5 per cent.)-namely, adeno-carcinoma in 20 (2.9 per cent.), sarcoma in 7 $<1$ per cent.), carcinoma in 6 ( 0.5 per cent.), chorionepithelioma in 2 ( 0.29 per cent.). Kelly and Cullen ${ }^{2}$ state that " in an examination of over 1,400 cases of myomatous uteri adeno-carcinoma was detected in the body of the uterus in about 1.7 per cent." Haultain, ${ }^{3}$ in a series of 120 cases, found malignant disease in 5.8 per cent.; adenocarcinoma in 5, and sarcoma in 2. Scharlieb, ${ }^{4}$ in a series of 100 cases, found 3 cases of malignancy ( 1 sarcoma, 2 adeno-carcinoma). Very similar figures could be given from other writers, such as Bland-Sutton, ${ }^{5}$ but it is unnecessary to do so, as it is obvious that the number of cases of malignant invasion and degeneration is, as already stated, from 3 to 5 per cent.

An interesting fact in connexion with these cases of malignant degeneration is the relative frequency of the occurrence in the later decades. Although occasionally one comes across cases of malignant degeneration at an early age, as a rule at least the fiftieth year has been reached before malignancy shows itself. This is strikingly seen in the 700 cases analysed by Ellice MacDonald-5 per cent. in the fifth decade, 1.7 per cent. in the sixth decade, and 23.7 per cent. in the seventh decade.

With such experiences it is not surprising that gynaecologists are becoming more and more afraid to leave f́bromyomata alone, and some are even going the length of saying that they should always be operated upon whenever recognized. The majority of us, however, in view of the fact that many fibromyomata give rise to no trouble and cause no interference with the course of pregnancy and parturition, are still disposed to tэmporize in many cases. The question, then, we have to face is When is it dangerous to temporize? We are all agreed that haemorrhage and pressure symptoms indicate imme diate interference, but what we wish to try to arrive at is the indications which render interference necessary, eren if these ordinarily recognized disturbances are not present. We wish to try to recognize the cases in which malignant degeneration or invasion has begun.

In a considerable number of cases we may suspect, and in many recognize, the malignancy. In cases of adenocarcinoma-and this is the most common variety of malignancy-curettage of the uterus and an examination of the scrapings will give us the information. But sometimes the uterine cavity is most difficult to explore by reason of its distortion by the tumours; and in cases of sarcoma curettage is generally of no value, as the malignant degeneration rarely commences in the endometrium. Pain is always suspicious, and in my experience pain is much more commonly a symptom in adeno-carcinoma which has invaded fibroids than in adeno-carcinoma attacking an - otherwise normal aterus. An increase of haemorrhage is also very general, and not infrequently there is a distinct increase in the swelling.

Lastly, there is the important fact that in a very large proportion of cases malignant invasion and degeneration do not occur until after the fortieth year, when the uterus is of little physiological value, and when one naturally has very little compunction in removing it. By the history, the age of the patient, and curettage, we will be able, I think, in most cases to recognize malignant changes, and can therefore safely allow a certain number of fibromyomata to remain unoperated upon. But the cases we should certainly never leave alone are those that continue to be associated with any disturbances, and, above all, with any haemorrhage after the fortieth year.

The operation of hysterectomy for fibroid tumours of the aterus has become one of such comparative safety that we can safely reckon on a death rate of not more than 2 per cent.

\section{THE TREATMENT OF}

\section{CHRONIC OÖPHORITIS AND ASSOCIATHD CONDITIONS.}

By T. CAMERON, M.B., C.M.GLasG.,

SURGEON, THE HOSPITAL FOR WOMEN, AND ASSISTANT SURGEO VICTORIA HOSPITAL FOR SICK CHILDREN, HOLL.

THE following is reported because a large number of such cases are met with in gynaecological practice and are difficult to deal with so as to give satisfactory after-results. The more conservative treatment which is now adopted, when in the course of an operation inflamed, adherent, prolapsed, and cystic ovaries have to be dealt with (or various combinations of these conditions), does not always meet with unqualified success. The removal of diseased elements in the ovary and the conservation of whatever part that may be deemed sufficiently healthy to retain, is good practice as far as it goes. Associated with adhesions which have to be divided or torn through, and a prolapsed condition of the ovary, we meet with conditions which require something more than the ordinary measures mentioned in textbooks, in order that reasonable assurance of completely relieving the patient's symptoms may be obtained. When adhesions are freed we are left with raw surfaces of more or less extent, both on the surface of the ovary and the peritoneal surface of Douglas's pouch, so that there is considerable risk that fresh adhesions may form. The mesentery of the ovary is often weak and stretched, so that, unless special precautions are adopted, not only may the ovary become adherent but it is apt to do so in a faulty position.

Before adopting the measures to be described later, I have usually stitched the ovary to the broad ligament or shortened the mesentery, with or without simultaneously performing a suspension of the uterus. This gave variable results-some good, others not. In estimating results, most importance has been attached to the presence or absence of pain. These cases always apply on account of pain in one form or another. It may be almost constant in character, and aggravated on the least exertion; usually there is dispareunia and severe dysmenorrhoea. Occasicnally defaecation aggravates the pain considerably.

No doubt there are cases of old-standing inflammation and adhesions of the ovaries in which there is little or no pain, but these do not come up for operation. The question-what is the main element in producing pain in these cases?-is interesting. It may be the direct effect of the inflammatory condition, just as in any other organ. In displaced ovaries the venous return seems to be interfered with, and the veins are often varicose. Sometimes the pain appears to be "neuralgic."

The nature of the numerous small cysts met with in many cases is also of interest. Olshausen suggests that they are true retention cysts - that is, due to sclerosis of the periphery of the ovary, which prevents the Graafian follicles from discharging their contents at the surface. Judging, however, from the large number of cysts sometimes found, their equality in size and often their distribution throughout the ovary, it appears to be more probable that there is an inflammatory action in the Graafian follicles which induces a condition of hydrops. I only mention the matter here because there is a probability that the pressure of these cysts may be another factor in producing pain in the ovary.

For practical purposes it may be assumed that each cause plays some part in the causation of pain.

In the course of an operation, when all adhesions have been dealt with and cysts dissected out of the ovaries, or a section of an ovary more markedly affected by cystic formation removed, the next step is to restore the ovary as much as possible, by stitching with fine catgut, so as to bring all raw surfaces into apposition, and renew as much as possible the general shape and contour of the organ.

In operating upon these cases, and in cases also in which there is a more acute degree of infection, such as cases of pyosalpinx, ovarian abscess, and so on, I have been struck by the wonderful immunity enjoyed by the anterior surface of the broad ligament as compared with the posterior. Whilst adhesions, the deposition of lymph, and all the other signs of an infective peritonitis are found 